
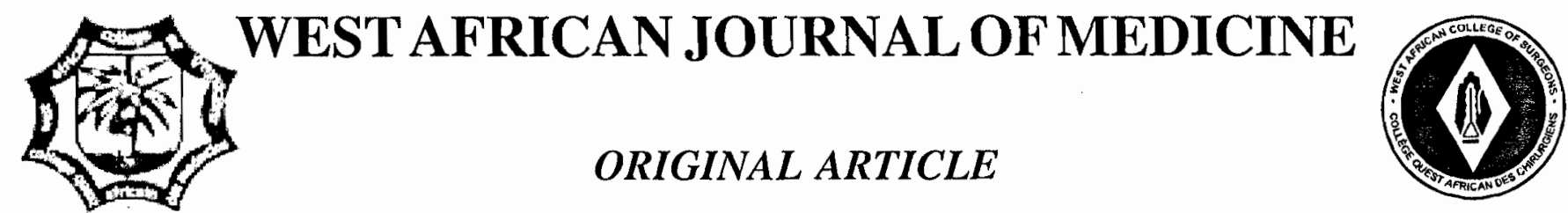

\title{
Evaluation of Alvarado Score as an Admission Criterion in Patients with Suspected Diagnosis of Acute Appendicitis.
}

\section{L'évaluation de score d'Alvarado comme un critère d'admission dans les malades avec le diagnostic présumé d'appendicite aiguë.}

\begin{abstract}
BACKGROUND: Patients with right iliac fossa pain present a diagnostic challenge to emergency room doctors when equivocal signs are present.

OBJECTIVE: To evaluate Alvarado score as an admission criterion in patients with suspected diagnosis of acute appendicitis.

METHODS: This was a prospective study of 100 consecutive patients who presented to the an emergency department with right iliac fossa pain and suspected diagnosis of acute appendicitis between January 2004 and December 2004. They were assessed using Alvarado score. Main outcome measures in relation to these scores were, patient's admission, patient's discharge, and whether patient had appendicitis or not.

RESULTS: The range of scores was 1-10. Seventy-four patients were admitted while 26 were discharged. Thirty-four patients with confirmed diagnosis of acute appendicitis had scores ranging from 5-10. No patient with score less than 5 had appendicitis. The sensitivity and negative predictive value reached $100 \%$ at scores below five, while specificity and positive predictive value reached $100 \%$ at the score of 10 .
\end{abstract}

A. O. Tade

CONCLUSION: The Alvarado score can be used as an objective criterion in selecting for admission patients with suspected diagnosis of acute appendicitis. Patients with scores of 4and below do not require admission since they turn out not to have acute appendicitis. WAJM 2007; 26(3): 210 - 212.

Keywords: Alvarado score, appendicitis, admission criterion, Diagnosis.

\section{RESUMÉ}

Contexte: Les malades avec la bonne douleur de fosse iliaque présentent un défi diagnostique aux médecins de pièce d'urgence quand les signes équivoques sont présents.

Objectif. Pour évaluer le score d'Alvarado comme un critère d'admission dans les malades avec le diagnostic présumé d'appendicite aiguës.

Méthodes: Ceci était une étude possible de 100 malades consécutifs qui ont présenté à l'un département d'urgence avec la bonne douleur de fosse iliaque et le diagnostic présumé d'appendicite aiguë entre le 2004 janvier et December2004. Ils ont été évalués le score d'Alvarado d'utilisation. Les mesures principales d'issue par rapport à ces scores étaient, l'admission du malade, la décharge du malade, et si le malade a eu l'appendicite ou pas.

Résultats: La gamme de scores était 1-10. Soixante-quatorze malades ont été admis pendant que 26 ont été déchargés. Les malades de trente-quatre avec le diagnostic confirmé d'appendicite aiguë scores eus étendant de 5-10. Aucun malade avec le score moins que 5 appendicite eue. La sensibilité et la valeur prophétique négative ont atteint 100\% aux scores au dessous de cinq, pendant que spécificité et la valeur prophétique positive ont atteint $100 \%$ au score de 10 .

Conclusion: Le score d'Alvarado peut être utilisé comme un critère objectif dans choisir pour les malades d'admission avec le diagnostic présumé d'appendicite aiguë. Les malades avec les scores de 4 et au dessous de n'exige pas l'admission puisque ils sont pour ne pas avoir l'appendicite aiguë. WAJM 2007; 26(3): $210-212$.

Mots clés: Le score d'Alvarado, l'appendicite

Department of Surgery, Olabisi Onabanjo, University Teaching Hospital, Sagamu, Ogun State, Nigeria.

Correspondence: Dr. A.O. Tade, P. O. Box 1303, Sagamu, Ogun State, Nigeria. 


\section{INTRODUCTION}

Right iliac fossa pain is a relatively common symptom of which acute appendicitis is an important differential diagnosis. Simple appendicitis can progress to perforation, with associated high morbidity and mortality. In some cases of acute appendicitis, surgeons have been inclined to operate when the diagnosis is probable rather than certain. Table 1: Alvarado Scoring System

\begin{tabular}{lc}
\hline Variable & Score \\
\hline Symptom & \\
Migratory right iliac fossa pain & 1 \\
Anorexia & 1 \\
$\quad$ Nausea and vomiting & 1 \\
Sign & \\
Right iliac fossa tenderness & 2 \\
Fever Temp $>37.3^{\circ} \mathrm{C}$ & 1 \\
Rebound tenderness in right & \\
iliac fossa \\
Laboratory test \\
$\quad$ Leucocytosis $\left(10 \times 10^{9} / \mathrm{L}\right)$ \\
$\quad \begin{array}{l}\text { Neutrophilic shift to the } \\
\text { left }>75 \%)\end{array}$ \\
\begin{tabular}{l} 
Total score \\
\hline
\end{tabular}
\end{tabular}

This clinical decision may lead to the removal of a normal appendix in $15 \%$ $30 \%$ of cases. ${ }^{1}$ In order to reduce this proportion, patients with equivocal signs are very often admitted to the surgical wards for observation. Alvarado score, first reported in $1986^{2}$, was designed as a diagnostic aid in acute appendicitis. The score which has a range of $1-10$, is based on three symptoms, three signs and two laboratory findings. (Table 1). Owen et al reported that there was no perforated appendicitis in patients with Alvarado score of less than $6^{3}$. This study was designed to evaluate the use of Alvarado score by accident and emergency room doctors as a criterion for admission into the surgical ward.

\section{MATERIALS AND METHODS}

This was a prospective study of one hundred consecutive adult patients who attended the emergency department with suspected diagnosis of acute appendicitis between January and December 2004. The patients were initially seen in the accident and emergency unit by the casualty officer who then referred the patient to the surgical unit with suspected diagnosis of appendicitis. The Alvarado score, which is based on three symptoms, three signs and two laboratory findings, was used to assess them. (Table 1). Patients were scored in the emergency department. Information concerning age, sex, diagnosis, Alvarado score, treatment offered and final diagnosis were recorded in a proforma and then analyzed. The decision for admission and surgery was made independent of the score and was recorded. Diagnosis of appendicitis was confirmed by both operative findings and histology. Patients who were discharged were given an appointment to attend the emergency department the next day.

In this study, normal appendicectomy was defined as a grossly normal appendix removed at surgery and confirmed as such histologically. Patients with generalized peritonitis and those with a palpable mass in the right iliac fossa were excluded from the study.

Results of the Alvarado score were analyzed for sensitivity, specificity, positive and negative predictive values with regards to acute appendicitis.

\section{Statistical analysis}

Sensitivity is defined as the fraction of those with the disease (appendicitis) who tested positive. Specificity is defined as the fraction of those without the disease (appendicitis) who tested negative. Positive predictive value is the proportion of all those with a positive test that had appendicitis. Negative predictive value is the proportion of all those with a negative test that did not have appendicitis.

In this study a positive test at an Alvarado score applied to those patients with that score and above, while a negative test applied to patients with a score below that value. This means that at an Alvarado test of five, a positive test is recorded for patients who score five

Table 3: Alvarado Score of all Patients and Eventual Outcome.

\begin{tabular}{llrrrrrrrrrl}
\hline Outcome & \multicolumn{10}{c}{ Alvarado score } & Total \\
\cline { 2 - 12 } & $\mathbf{1}$ & $\mathbf{2}$ & $\mathbf{3}$ & $\mathbf{4}$ & $\mathbf{5}$ & $\mathbf{6}$ & $\mathbf{7}$ & $\mathbf{8}$ & $\mathbf{9}$ & $\mathbf{1 0}$ & \\
\hline Discharged & 1 & 6 & 14 & 3 & 2 & 0 & 0 & 0 & 0 & 0 & 26 \\
Admitted & 0 & 3 & 7 & 10 & 11 & 13 & 9 & 12 & 8 & 1 & 74 \\
Total & 1 & 9 & 21 & 13 & 13 & 13 & 9 & 12 & 8 & 1 & 100 \\
Appendicitis & 0 & 0 & 0 & 0 & 4 & 7 & 6 & 9 & 7 & 1 & 34 \\
\hline
\end{tabular}

were discharged, 18 of whom kept the appointment and were found to be well, requiring no further treatment. The results of the laboratory tests were sometimes delayed for up to six hours. Table 3 shows the Alvarado scores of all the patients and the outcome. Figure 1 shows the graphic presentation of sensitivity, specificity, negative and positive predictive values of the Alvarado Score system. Sensitivity and negative predictive values reached $100 \%$ at scores below 5, indicating that patients with scores below five did not

Table 2: Final diagnosis of admitted patients.

\begin{tabular}{lc}
\hline Diagnosis & No (\%) of patients \\
\hline Acute appendicitis* & $38(51.4)$ \\
Non-specific abdominal pain & $5(20.3)$ \\
Acute P.I.D. & $4(5.3)$ \\
Right ureteric colic & $1(1.4)$ \\
Non specific enteritis & $7(9.5)$ \\
Typhoid fever & $2(2.7)$ \\
Urinary tract infection & $3(4.1)$ \\
Ovulation related pain & $4(5.3)$ \\
\hline Total & $\mathbf{7 4 ( 1 0 0 )}$ \\
\hline
\end{tabular}

* Had appendicectomy and includes four non- inflamed appendices. ${ }^{*}$ P.I.D., pelvic inflammatory disease.

and over, while a negative test is recorded for patients who score below five.

\section{RESULTS}

There were 100 patients, comprising of 63 males and 37 females with ages ranging from 17 years to 56 years (mean 34 years). Sixty-five $(65 \%)$ were aged 20-40years. Seventy-four patients were admitted to the surgical wards while 26 patients were discharged. Thirty-eight patients had appendicectomy, four of these were normal appendices $(10.5 \%)$. Seven patients $(18.4 \%)$ had perforated appendicitis. Table 2 shows the final diagnosis of the admitted patients. Fortyfour patients had scores less than 5 , out of whom 20 were admitted, none required appendicectomy. Twenty-four patients 


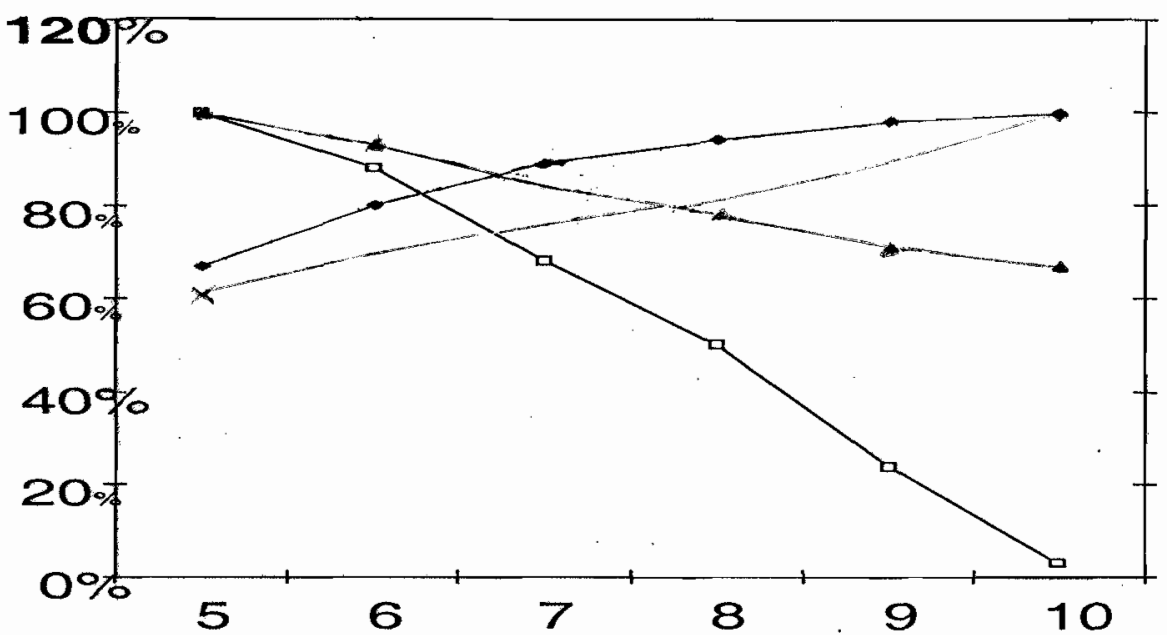

Figure 1: Diagnostic performance of Alvarado Score. Sensitiviy (squares), specificity (rhomdoids) negative predictive (triangles) and positive predictive (crosses) values. The scores are on the $\mathrm{x}$-axis

have appendicitis. The specificity and positive predictive reached $100 \%$ with a score of 10 , indicating that all patients with such score had appendicitis.

\section{DISCUSSION}

Appendicitis still poses some diagnostic challenge in patients with unclear presentation. Many methods have been investigated to try to reduce the removal of a normal appendix without increasing the perforation rate in this category of patients. Radiological methods such as ultrasonography and computed tomography, as well as laparoscopy are all methods that have been investigated previously. ${ }^{4-6}$ Many diagnostic scores have been advocated but most are complex and difficult to implement in a clinical situation. ${ }^{7}$ The Alvarado score, first described in 1986, is a simple scoring system that can be instituted easily in the accident and emergency setting. ${ }^{2}$ Previous studies had found that the Alvarado score was most accurate only at the two extremes of the score and patients with scores of one to four may require no treatment. ${ }^{5}$ Good clinical acumen remains the mainstay of correct diagnosis of appendicitis. ${ }^{8}$

General practitioners and emergency physicians face a difficult problem when presented with a patient with right iliac fossa pain with equivocal signs. The decision to admit or discharge these patients is not always straightforward. This may be compounded by the relative lack of surgical experience of many junior doctors who may need to make this decision at the emergency department, especially in the absence of experienced surgeons. Figure 1 shows the analysis of he Alvarado score in the patients for sensitivity, specificity, positive and . eegative predictive values. Sensitivity and negative predictive values reached $100 \%$ at scores below five, indicating that patients with scores below 5 did not have appendicitis. The specificity and positive predictive reached $100 \%$ with a score of 10 , indicating that all patients with such score had appendicitis. Previous study by Owen et al has found that no patient with a score below six had perforated appendicitis.

In this study no patient with a score less than 5 had appendicitis, if this had been used as the admission criterion, 20 patients who were admitted could have been observed as outpatients, thus reducing the admission rate by $18 \%$. It is important to closely follow up these patients to prevent delay in diagnosing worsening clinical status. Our study however showed that none of the patients in this group required appendicectomy. It is also important to emphasize that the scoring may not be accurate in patients who are unable to give a proper history, such as those with communication problems. $^{2}$ The Alvarado score can be used as an objective criterion in selecting for admission patients with suspected appendicitis. In this study patients with scores of four and less did not have appendicitis and required no admission. It is important to advise such patients to return for review 24 hours later or if symptoms worsen.

\section{ACKNOWLEDGEMENT}

The assistance of surgical residents in data collection is hereby acknowledged.

\section{REFERENCES}

1. Douglas CD, Macpherson NE, Davidson PM, Gani JS. Randomized controlled trial of ultrasonography in diagnosis of acute appendicitis incorporating the Alvarado score. $B M J$ 2000; 321: 919 - 922 .

2. Alvarado A. A practical score for the early diagnosis of acute appendicitis. Ann Emerg Med 1986; 15: 557 - 564.

3. Owen TD, Williams H, Stiff G, Jenkinson LR, Rees BI. Evaluation of Alvarado score in acute appendicitis. $J$ $R$ Soc Med 1992; 85:87 - 89.

4. Shrivastava UK, Gupta A, Sharma D. Evaluation of Alvarado score in the diagnosis of acute appendicitis. Trop Gastroenterol. 2004; 25: 184- 186.

5. Winn RD, Laura S, Douglas C, Davidson P, Gani JS. Protocol-based approach to suspected appendicitis: incorporating the Alvarado score and outpatient antibiotic. ANZ J Surg 2004; 74: $324-329$.

6. Chan MY, Tan C, Chiu MT, Ng YY. Alvarado score: An admission criterion in patients with right iliac fossa pain. Surgeon 2003; 1: $39-41$.

7. Ohmann C, Yang Q, Franke C. Diagnostic scores for acute appendicitis. Abdominal Pain Study Group. Eur J Surg 1995; 161:273-281

8. Izbicki JR, Knoefel WT, Wilker DK, Mandelkow HK, Muller K, Siebeck M et al. Accurate diagnosis of acute appendicitis: a retrospective and prospective analysis of 686 patients. Eur J Surg 1992; 158: 227 - 231 . 